\title{
Seroprevalence and comparison of different serological tests for brucellosis detection in small ruminants
}

\author{
Dashrath B. Sadhu $^{1}$, H. H. Panchasara ${ }^{1}$, H. C. Chauhan ${ }^{2}$, D. R. Sutariya ${ }^{1}$, V. L. Parmar $^{1}$ and H. B. Prajapati ${ }^{1}$
}

1. Department of Veterinary Medicine, Livestock Research Station, Sardarkrushinagar Dantiwada Agricultural University, Sardarkrushinagar, Dantiwada, Gujarat, India; 2. Department of Animal Biotechnology, College of Veterinary Science \& Animal Husbandry, Sardarkrushinagar Dantiwada Agricultural University, Sardarkrushinagar, Dantiwada, Gujarat, India.

Corresponding Author: Dashrath B. Sadhu, e-mail: dr.dashrathsadhu@gmail.com, HHP: harshadlrs@yahoo.co.in, HCC: dr.chauhan123@gmail.com, DRS: dr.dren087@gmail.com, VLP: viki07290@gmail.com, HBP: hit.vet305@gmail.com Received: 16-12-2014, Revised: 22-03-2015, Accepted: 30-03-2015, Published online: 04-05-2015

doi: 10.14202/vetworld.2015.561-566. How to cite this article: Sadhu DB, Panchasara HH, Chauhan HC, Sutariya DR, Parmar VL, Prajapati HB (2015) Seroprevalence and comparison of different serological tests for brucellosis detection in small ruminants, Veterinary World 8(5):561-566

\begin{abstract}
Aim: The aim was to study the seroprevalence and efficacy of the different serological tests used for detection of antibody against Brucella species in small ruminants of Banaskantha district of North-Gujarat.

Materials and Methods: Total 1000 serum samples comprising of 485 from sheep and 515 from goat tested for detection of antibodies against the Brucella species by three different serological tests viz., Rose bengal plate test (RBPT), Standard tube agglutination test (STAT), and Indirect Enzyme-linked immunosorbent assay (I-ELISA).

Results: The seroprevalence of brucellosis in small ruminants was $11.30 \%, 11.10 \%$, and $8.80 \%$ by RBPT, STAT, and I-ELISA, respectively. The seroprevalence of brucellosis was found to be higher in sheep than goats. The sensitivity of RBPT was found slight more than STAT, but the specificity of both tests was same. In this study, the overall agreement of RBPT and STAT with I-ELISA was found $92.50 \%$ and $92.30 \%$ in small ruminants, respectively.

Conclusion: I-ELISA was a better serological test as compared to RBPT and STAT in the sense of sensitivity, specificity, and rapidity and it could be advocated for screening of brucellosis in sheep and goats.
\end{abstract}

Keywords: brucellosis, seroprevalence, serological test, small ruminant.

\section{Introduction}

Brucella is a Gram-negative facultative intracellular organism responsible for a variety of disease conditions and having zoonotic significance. Brucellosis is caused by bacteria of the genus Brucella and is reported worldwide causing abortion, infertility, retained placenta, endometritis in females and to a smaller extent, orchitis, and infection of the accessory sex glands in males [1].

Brucellosis in India is a very common but often neglected disease [2]. Brucellosis due to B. melitensis is widespread in India and major cause of abortion in small ruminants imposing economic loss due to an adverse effect on total animal protein supplies and severe hazard to human health $[3,4]$. Sheep brucellosis can be divided into classical brucellosis and ram epididymitis. Ram epididymitis is caused by non-zoonotic agent $B$. ovis, while classical brucellosis is caused by $B$. melitensis and constitutes a major public health threat equal to goat brucellosis [5]. There are about 500,000 new human cases of brucellosis reported annually worldwide making it the most common zoonosis [6]. Sulima and Venkataraman [7] calculated the average annual economic loss due to brucellosis per animal on

Copyright: The authors. This article is an open access article licensed under the terms of the Creative Commons Attributin License (http:// creative commons.org/licenses/by/2.0) which permits unrestricted use, distribution and reproduction in any medium, provided the work is properly cited. sheep was found to be INR. 1180/- and on goats INR. 2121.82.

Brucellosis appears to be increase in recent times, perhaps due to increased trade and rapid movement of livestock [2]. Free grazing and movement with frequent mixing of flocks of sheep and goats are the main mode of disease transmission resulting in high prevalence and wide distribution of brucellosis in these animals in India [8].

Status of the diseases in small ruminants in the country can be known only through effective sero-monitoring using serological tests and random sampling methods for the disease. The economic importance of brucellosis in sheep and goats requires the use of sensitive and rapid diagnostic methods. Diagnosis of $B$. ovis and B. melintensis infection is based on clinical examination, serological tests, biotechnological techniques, and isolation $[9,10]$. The laboratory isolation and identification of Brucella organisms are most reliable methods of diagnosis but are not successful always, is not practicable in terms of time and labor for field and laboratory personnel when large numbers of animals are involved and also cumbersome and pose great risk to the laboratory personnel. The biotechnological procedures require the establishment of advanced laboratories and trained persons.

Rose bengal plate test (RBPT) is simple and easy to perform and can be used as herd screening test at remote places. Joint FAO/WHO Expert Committee on Brucellosis recommended the use of RBPT as a useful 
screening test for diagnosis of $B$. melitensis infection in sheep and goats [11]. Standard tube agglutination test (STAT) quantifies total agglutinating antibodies and higher detection rates had been reported through STAT in sheep and goat [12]. Recently, Enzymelinked immunosorbent assay (ELISA) has taken over as an important serological tool in the diagnosis of brucellosis because of its economy, sensitivity, specificity, rapidity, reproducibility, and easy interpretation through colorimetric end product [13]. Enzyme immunoassays are superior to all other tests in terms of specificity and sensitivity [12]. Due to non-availability of a gold standard test except isolation of organism which is a cumbersome process the improvement and validation of available serological tests is a needed as it enhances the specificity and sensitivity of the test.

Small ruminants play a significant role in supporting the livelihood system of the rural poorest men and women. More than $98 \%$ of sheep and goats are owned by the small, marginal, and landless illiterate farmers of the villages. They are unaware about brucellosis disease. Gujarat state is known for its rich biodiversity in most of the livestock species. Banaskantha district has 309 thousand goats and 161 thousand sheep population [14]. Goat and sheep-rearing continues to be a backward profession and thus has acquired very less attention. Thus, the aim of the present study was sero-screening of brucellosis in the cases of abortion and various reproductive disorders in sheep and goats by using three serological tests viz., RBPT, STAT, and indirect -ELISA and to evaluate their comparative efficacy.

\section{Materials and Methods}

\section{Ethical approval}

This study was approved by Animal Ethics Committee of Sardarkrushinagar Dantiwada Agricultural University

\section{Study area}

The seroprevalence of brucellosis carried out in small ruminants of Banaskantha district of Gujarat, India. Banaskantha district is situated in Northwestern part of the Gujarat. The district is encompassed by 23.03-24.45 North latitude and 71.21-73.02 East longitude. The district is surrounded by Rajasthan state in East-North, Mehsana in South and Patan and Kutch district in West. Next to the desert is the border of Pakistan. The normal climate of the district and mainly three seasons viz. summer, monsoon, and winter. The normal rainfall of the district could be considered at $601 \mathrm{~mm}$. It is the second largest district in the state.

\section{Samples}

Total 1000 serum samples of small ruminants comprising 485 from sheep and 515 from goats, having the history of abortion and reproductive disorders like endometritis, retention of placenta, infertility and repeat breeding, were randomly collected from different 17 locations of six taluka viz., Bhabhar, Dantiwada, Deesa, Deodar, Dhanera and Palanpur of Banaskantha district of North Gujarat during March, 2013 to March,2014. The samples were stored at $-20^{\circ} \mathrm{C}$ until they were used. All the serum samples tested for the presence of Brucella antibodies by using three serological tests viz., RBPT, STAT, and I-ELISA.

\section{RBPT protocol}

The RBPT was performed as per the procedure described by Alton et al. [15]. The RBPT antigen was procured from the Institute of Animal Health and Veterinary Biologicals (IAH and VB), Hebbal, Bangalore, Karnataka, India. To perform the test, antigen and serum were brought to the room temperature. The bottle containing antigen was shaken well to ensure homogenous suspension. Then after, one drop $(0.03 \mathrm{ml})$ of serum sample and antigen was taken on the same slide using different micropipette and mixed thoroughly using a spreader. The slide was rotated for 4 min and observed immediately then after 4 min for results. A result was considered as positive when there was noticeable agglutination found after $4 \mathrm{~min}$ for results (Figure-1).

\section{Stat protocol}

The STAT was performed as per the method described by Alton et al. [15]. The Brucella abortus plain antigen was procured from Institute of Animal Health and Veterinary Biologicals (IAH and VB), Hebbal, Bangalore, Karnataka, India. In order to perform the test, $0.8 \mathrm{ml}$ of $0.5 \%$ phenol saline was taken in the first agglutination tube whereas $0.5 \mathrm{ml}$ of the same was taken in remaining four agglutination tubes placed in a rack. Then after $0.2 \mathrm{ml}$ of serum sample was added in the first tube and mixed well by shaking. The $0.5 \mathrm{ml}$ of diluted serum was transferred from first to the second tube and the process was repeated up to the fifth tube. The $0.5 \mathrm{ml}$ of diluted serum was discarded from the last tube and $0.5 \mathrm{ml}$ of Brucella abotus plain antigen was added to each tube to get final dilution of $1: 10,1: 20,1: 40,1: 80$, and $1: 160$ in first, second, three, four, and fifth tube, respectively. A control tube was set up to simulate $50 \%$ agglutination by mixing $0.5 \mathrm{ml}$ antigen and $1.5 \mathrm{ml}$ of $0.5 \%$ phenol saline in an agglutination tube. All six tubes incubated at $37^{\circ} \mathrm{C}$ for $20 \mathrm{~h}$ before observation. Sera samples showing agglutination at 1:20 (40 IU) titer per $\mathrm{ml}$ of serum or above was considered as to be positive (Figure-2).

\section{I-ELISA protocol}

The I-ELISA was performed using the Protein-G based kit for Caprine and Ovine Brucellosis

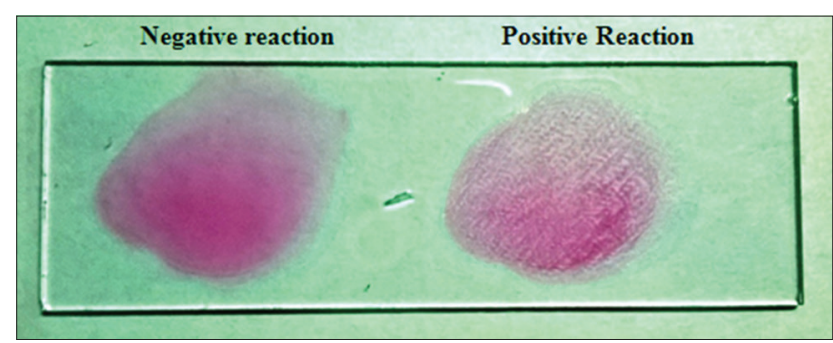

Figure-1: Rose Bengal plate test. 
manufactured by Project Directorate on Animal Disease Monitoring and Surveillance, Hebbal, Bangalore, Karnataka, India using smooth lipopolysaccharide for coating. In order to perform the test, samples, reagents, and plate(s) were brought to room temperature prior to starting the test. Using a pipette set at $100 \mu \mathrm{l}$, antigen was transferred into each well of the microtiter plate. The sides of the plate were tapped to ensure even distribution of the antigen over the bottom of each well. The plate was covered with aluminum foil/lid and incubated overnight at $4{ }^{\circ} \mathrm{C}$ in the refrigerator. After incubation, the plate was washed with $100 \mu \mathrm{l}$ of washing buffer. For manual washing, the contents of the wells were dumped into a sink and the free content was removed by striking. The plate inverted on a clean paper towel for 4 times. Immediately, the wells were filled with washing buffer using a multichannel pipette and the washing procedure was repeated for 2 times. The diluted $100 \mu 1$ test sera sample was dispensed in duplicate wells (two-wells) and three control sera (High, moderate, and negative sera) in quadruplicate wells (four-wells) of the microtiter plate as per the layout provided and incubated at $37^{\circ} \mathrm{C}$ for $1 \mathrm{~h}$ on the ELISA plate shaker@300 rpm. The plate was removed from the shaker and washed three times with washing buffer. Then $100 \mu \mathrm{l}$ of working dilution of chromogen solution was added to each wells of the microtiter plate and incubated at room temperature in dark place for 7 min or until a visible color developed in the strong positive wells by covering with aluminum foil. Immediately after the color developed, further reaction was stopped by adding $50 \mu \mathrm{l}$ of stopping solution to each well of the microtiter plate. Immediately after adding the stopping solution, the plate was read in the ELISA plate reader at $492 \mathrm{~nm}$ wavelength (Figure-3). The optical density (OD) values of the test controls in each ELISA test performed should fall within the defined upper control limit (UCL) and lower control limit (LCL) for acceptance and rejection of the test. For positive control, OD values of UCL, and LCL should be between 1.2 and 0.06 , respectively. While for the negative controls, OD values of UCL, and LCL should be between 0.20 and 0.09 , respectively. Percent positivity (PP) value was calculated as follows:

$$
\mathrm{PP}=\frac{\text { Average OD value of test serum }}{\text { Median OD of the strong positive sera }} \times 100
$$

Sample that gave more than 55\% PP value was considered as positive, below $55 \%$ was considered as negative if sample showed PP value 55\% then it was retested.

\section{Statistical analysis}

A Chi-square $\left(\chi^{2}\right)$ test was done to compare the prevalence of brucellosis (in percent) between species. Significance was determined at 5\% level. The difference was considered statistically significant if

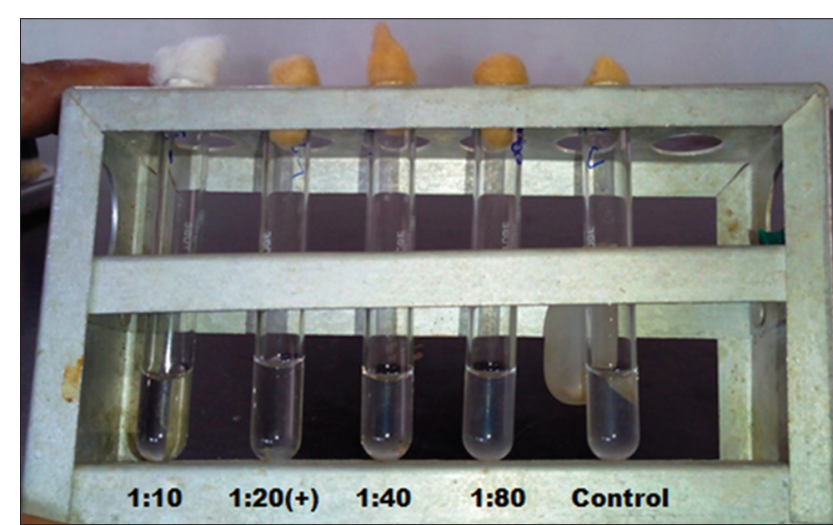

Figure-2: Serum tube agglutination test, Tube No. 1 $2=$ Positive reaction, Tube No. 3, 4=Negative reaction, Tube $\mathrm{C}=$ Control

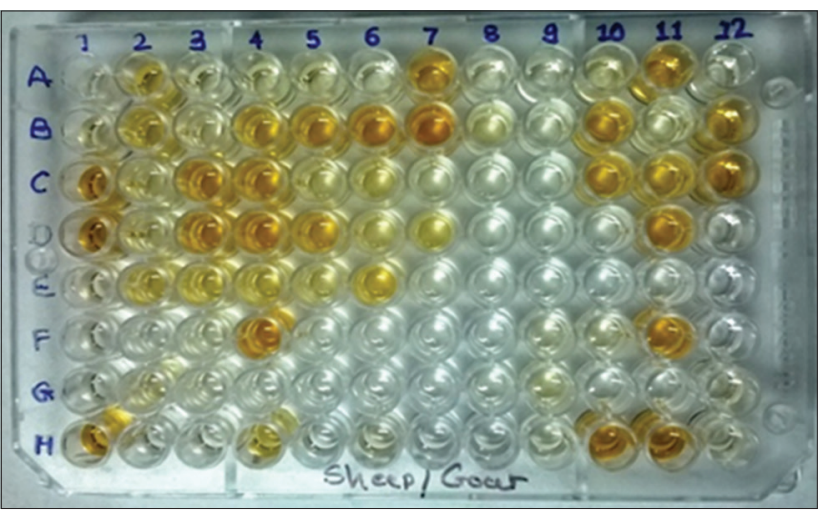

Figure-3: Microtiter plate showing the results of I-ELISA, Well A1 and B1-Conjugate control, Well C1 and D1 - Strong positive control, Well E1 and F1 - Moderately positive control, Well indicate positive reaction of field sera - H1, B2, C3, D3, B4, C4, D4, F4, B5, D5, B6, A7, B7, B10, C10, A11, $\mathrm{C} 11, \mathrm{D} 11, \mathrm{~F} 11, \mathrm{H} 11, \mathrm{~B} 12$, and $\mathrm{C} 12$, rest of well - indicate negative reaction.

the $p<0.05$. The comparative efficacy of RBPT and STAT to I-ELISA determined with regards to their sensitivity, specificity, and overall agreement in the diagnosis of small ruminant brucellosis. Cross tabulation of RBPT and STAT with I-ELISA, considering I-ELISA as a gold standard test were recorded as per Samad et al. [16] to determine relative sensitivity, specificity, and overall agreement of RBPT and STAT.

Sensitivity: It is the capacity of the test to detect diseased animals, when compared with the gold standard test $(\mathrm{a} / \mathrm{a}+\mathrm{c} \times 100)$.

Specificity: It is the capacity of the test to detect non-diseased animals, when compared with the gold standard test $(\mathrm{d} / \mathrm{b}+\mathrm{d} \times 100)$.

Overall agreement: Is the proportional similarity of the results of both the tests $(\mathrm{a}+\mathrm{d} / \mathrm{N} \times 100)$.

\section{Results and Discussion}

\section{Seroprevalence}

The overall seroprevalence of brucellosis in small ruminants was $11.30 \%, 11.10 \%$, and $8.80 \%$ by RBPT, STAT, and I-ELISA, respectively. Statistically significant $(\mathrm{p}<0.05)$ higher seroprevalence was found in sheep $(14.64 \%, 14.43 \%$, and $11.75 \%)$ than in goats 
$(8.15 \%, 7.96 \%$, and $6.02 \%)$ by RBPT, STAT, and I-ELISA test, respectively (Table-1).

Earlier, similar seroprevalence of brucellosis was reported by Shome et al. [17] 9.95\% by RBPT and $7.36 \%$ by I-ELISA in sheep and goats of Rajasthan, Gujarat, and Karnataka state and Singh et al. [18] reported higher prevalence of brucellosis in ovine species as compared to caprine species by multiple serological tests.

Teshale et al. [19] reported $9.7 \%$ positivity by I-ELISA in sheep and goats of pastoral regions of Ethiopia. Ashenafi et al. [20] reported 9.4\% positive samples by RBPT in sheep and goats of the pastoral region of Afar. In comparison to the present study high seroprevalence was obtained by Esendal et al. [21], who reported $37.6 \%$ and $44.4 \%$ by RBPT and STAT, respectively, while $26.99 \%$ by I-ELISA according to Valarmathy et al. [22] in ovine-caprine sera. The overall prevalence of brucellosis in sheep of Kashmir valley was $6.50 \%$ [23]. The reason for this seroprevalence in small ruminants could be variation in management practices, frequent introduction of new animals without proper serological testing, no any practice of isolation, and removal of animals with high incidence of abortions, frequent mixing of one infected flock to another, mixing of different species, no any proper disposals of aborted fetus and placental membranes, and contamination of healthy animal to contaminated feed and water.

In the present study, when three serological tests were compared, highest seropositivity was found by RBPT $(11.30 \%)$ followed by STAT $(11.10 \%)$ and least by I-ELISA $(8.80 \%)$. Similar results noted by Rahman et al. [24] who found highest seroprevalence of brucellosis by RBPT (5.83\%) followed by STAT $(4.17 \%)$ and least by I-ELISA $(2.50 \%)$ in goats and highest seroprevalence of brucellosis by RBPT $(3.75 \%)$ followed by STAT $(2.50 \%)$ and least by I-ELISA $(1.25 \%)$ in sheep. Din et al. [25] also found RBPT $(11.33 \%)$ was more sensitive than SPAT $(9.33 \%)$ and STAT $(7.66 \%)$ in goats. However, Kotadiya [26] reported higher seroprevalence by I-ELISA (18.20\%) followed by RBPT $(11.38 \%)$ and least by STAT $(9.44 \%)$ in sheep of Gujarat. Shome et al. [17] reported highest seroprevalence of brucellosis by RBPT $(9.95 \%)$ followed by I-ELISA $(7.36 \%)$ and least by STAT (5.67\%) in sheep and goats of Rajasthan, Gujarat, and Karnataka states of the India. It may be due to the ability of each test to detect different antibody classes. The I-ELISA detected least positivity of brucellosis while RBPT detected higher positivity of brucellosis in small ruminant. It could be due to I-ELISA is a quantitative test which detects only IgG while STAT quantifies both IgM and IgG (but mainly IgM) and RBT qualitatively detects both IgM and IgG. Beside this, RBPT was highly sensitive but heterospecific. Infection due to organisms such as Vibrio cholera, Yersinia enteroclitica 0:9, Pasteurella spp, Salmonella or some other members of the Brucellaceae family could give false positive results in RBPT than STAT and I-ELISA.

\section{Sensitivity, specificity, and overall agreement}

In the present study, the sensitivity of RBPT and STAT was $71.59 \%$ and $69.32 \%$, respectively while specificity was $94.52 \%$ for both the tests, considering I-ELISA as a gold standard test. Thus, RBPT was more sensitive than STAT but the specificity of both tests was similar (Table-2). Similar results also obtained in caprine and ovine species individually (Tables-3 and 4).

Similarly, Tayshete [27] reported $71.42 \%$ sensitivity of both RBPT and STAT and 100\% specificity of both RBPT and STAT in small ruminants, considering I-ELISA as a gold standard test. Awandkar et al. [28] noted that RBPT was more sensitive than STAT. In contrast, Hassanain and Ahmed [29] reported STAT (100\%) was more sensitive than RBPT (83.3\%) for diagnosis of brucellosis. Hence, I-ELISA has been found to detect antibodies in chronically infected animals while RBPT detects antibodies only in acutely infected animals and it is high sensitive and specific for antibody detection; this method has been recommended to be stable and suitable test for routine diagnosis of brucellosis in small ruminants.

The overall agreement of RBPT and STAT with I-ELISA was found $92.50 \%$ and $92.30 \%$ in small ruminants, respectively (Table-2). Similar results also obtained in caprine and ovine species individually (Tables-3 and 4). Similarly, Kotadiya [26] reported overall agreement of RBPT and STAT with I-ELISA was $93.78 \%$ and $91.25 \%$, respectively and concluded that I-ELISA to be a better serological test as compared to RBPT and STAT and it could be advocated for screening of sheep for brucellosis. According to ICAR Annual Report [30], RBPT showed the least relative sensitivity than I-ELISA in both sheep and goats, taking complement fixation test as gold standard and I-ELISA could be used as a validated test for

Table 1: Comparison of all three serological test with respect to species.

\begin{tabular}{lcccc}
\hline Species & $\begin{array}{c}\text { Number of sera } \\
\text { sample tested }\end{array}$ & $\begin{array}{c}\text { RBPT } \\
\text { positive (\%) }\end{array}$ & $\begin{array}{c}\text { STAT } \\
\text { positive (\%) }\end{array}$ & $\begin{array}{c}\text { I-ELISA } \\
\text { positive (\%) }\end{array}$ \\
\hline Goats & 515 & $42(8.15)$ & $41(7.96)$ & $31(6.02)$ \\
Sheep & 485 & $71(14.64)$ & $70(14.43)$ & $57(11.75)$ \\
Total & 1000 & $113(11.30)$ & $111(11.10)$ & $88(8.80)$ \\
$\chi^{2}$ test ( $p$ value) & & $10.48 *(p=0.002)$ & $10.60 *(p=0.001)$ & $10.23 *(p=0.002)$ \\
\hline
\end{tabular}

*Significant at $5 \%$ Level $(p<0.05)$, RBPT=Rose Bengal plate test, STAT=Standard tube agglutination test, I-ELISA =Indirect enzyme-linked immunosorbent assay 
Table 2: Sensitivity, specificity, and overall agreement of RBPT and stat in comparison to I-ELISA for detection of Brucella antibodies in small ruminants.

\begin{tabular}{|c|c|c|c|c|c|c|}
\hline \multirow[t]{2}{*}{ Test } & \multicolumn{2}{|c|}{ I-ELISA } & \multirow[t]{2}{*}{ Total } & \multirow[t]{2}{*}{ Sensitivity (\%) } & \multirow[t]{2}{*}{ Specificity (\%) } & \multirow[t]{2}{*}{ Overall agreement (\%) } \\
\hline & Positive & Negative & & & & \\
\hline \multicolumn{7}{|l|}{ RBPT } \\
\hline Positive & 63 & 50 & 113 & 71.59 & 94.52 & 92.50 \\
\hline Negative & 25 & 862 & 887 & & & \\
\hline Total & 88 & 912 & 1000 & & & \\
\hline \multicolumn{7}{|l|}{ STAT } \\
\hline Positive & 61 & 50 & 111 & 69.32 & 94.52 & 92.30 \\
\hline Negative & 27 & 862 & 889 & & & \\
\hline Total & 88 & 912 & 1000 & & & \\
\hline
\end{tabular}

RBPT=Rose Bengal plate test, STAT=Standard tube agglutination test, I-ELISA=Indirect enzyme-linked immunosorbent assay

Table 3: Sensitivity, specificity, and overall agreement of RBPT and stat in comparison to I-ELISA for detection of Brucella antibodies in goat.

\begin{tabular}{|c|c|c|c|c|c|c|}
\hline \multirow[t]{2}{*}{ Test } & \multicolumn{2}{|c|}{ I-ELISA } & \multirow[t]{2}{*}{ Total } & \multirow[t]{2}{*}{ Sensitivity (\%) } & \multirow[t]{2}{*}{ Specificity (\%) } & \multirow[t]{2}{*}{ Overall agreement (\%) } \\
\hline & Positive & Negative & & & & \\
\hline \multicolumn{7}{|l|}{ RBPT } \\
\hline Positive & 19 & 23 & 42 & 61.29 & 95.25 & 93.20 \\
\hline Negative & 12 & 461 & 473 & & & \\
\hline Total & 31 & 484 & 515 & & & \\
\hline \multicolumn{7}{|l|}{ STAT } \\
\hline Positive & 18 & 23 & 41 & 58.06 & 95.25 & 93.01 \\
\hline Negative & 13 & 461 & 474 & & & \\
\hline Total & 31 & 484 & 515 & & & \\
\hline
\end{tabular}

RBPT=Rose Bengal plate test, STAT=Standard tube agglutination test, I-ELISA=Indirect enzyme-linked immunosorbent assay

Table 4: Sensitivity, specificity, and overall agreement of RBPT and stat in comparison to I-ELISA for detection of Brucella antibodies in sheep.

\begin{tabular}{|c|c|c|c|c|c|c|}
\hline \multirow[t]{2}{*}{ Test } & \multicolumn{2}{|c|}{ I-ELISA } & \multirow[t]{2}{*}{ Total } & \multirow[t]{2}{*}{ Sensitivity (\%) } & \multirow[t]{2}{*}{ Specificity (\%) } & \multirow[t]{2}{*}{ Overall agreement $(\%)$} \\
\hline & Positive & Negative & & & & \\
\hline \multicolumn{7}{|l|}{ RBPT } \\
\hline Positive & 44 & 27 & 71 & 77.19 & 93.69 & 91.75 \\
\hline Negative & 13 & 401 & 414 & & & \\
\hline Total & 57 & 428 & 485 & & & \\
\hline \multicolumn{7}{|l|}{ STAT } \\
\hline Positive & 43 & 27 & 70 & 75.44 & 93.69 & 91.55 \\
\hline Negative & 14 & 401 & 415 & & & \\
\hline Total & 57 & 428 & 485 & & & \\
\hline
\end{tabular}

RBPT=Rose Bengal plate test, STAT=Standard tube agglutination test, I-ELISA=Indirect enzyme-linked immunosorbent assay

diagnosis of brucellosis in small ruminants. Hence, I-ELISA found to be a better serological test as compared to RBPT and STAT and it could be advocated for screening of small ruminants for brucellosis.

\section{Conclusion}

On the basis of the present study, we conclude that seroprevalence of brucellosis was prevalent in small ruminants of the study area. Seroprevalence of brucellosis was significantly more frequent in sheep as compared to goats. When three serological tests were compared, highest seropositivity was found by RBPT followed by STAT and least by I-ELISA. Sensitivity and specificity of I-ELISA were higher than RBPT and STAT for the detection of Brucella antibodies. Thus, I-ELISA is a better serological test as compared to RBPT and STAT and it is advocated for screening and diagnosis of brucellosis in small ruminants. Although, there is a need of further evaluation using serum samples from bacteriological isolation positive animal. Beside this, control and prevention programs should be started at the state and national levels for decreasing the incidence of brucellosis. For this an extension education campaign about risk factors of disease, economic, and zoonotic importance of disease should be stated particularly in the high-risk areas, among veterinary practitioners and livestock owners and regular sero-surveillance of the disease needed to know the status of control and prevention programs. 


\section{Authors' Contributions}

The present study was a part of DBS's original research work during his M.V.Sc thesis program. HHP conceptualized the aim of the study, designed, planned and supervised the experiment and corrected the manuscript. Collection of samples, execution of the experimental study, collation and analysis of data, interpretation of the results, and drafting the manuscript was done by DBS. HCC, VLP, HBP and DRS helped in analyses, draft, and revision of the manuscript. All authors read and approved the final manuscript.

\section{Acknowledgments}

The authors are thankful to the Dean, College of Veterinary Science and Animal Husbandry, SDAU; Professor and Head, Department of Veterinary Medicine, College of Veterinary Science and Animal Husbandry, SDAU and Professor and Head, Department of Animal Biotechnology, College of Veterinary Science and Animal Husbandry, SDAU, Sardarkrushinagar, Dantiwada, Gujarat for providing necessary infrastructure and fund for this postgraduate research.

\section{Competing Interests} interests.

The authors declare that they have no competing

\section{References}

1. Mustafa, Y.S., Awan, F.N. and Hazeen, K. (2011) Prevalence of brucellosis in sheep and goat. Sci. Int., 23(3): 211-212.

2. Renukaradhya, G.J., Isloor, S. and Rajasekhar, M. (2002) Epidemiology, zoonotic aspects, vaccination and control/ eradication of brucellosis in India. Vet. Microbiol., 90(1-4): 183-195.

3. Abeer, H.A., Shawkat, Q.L. and Al-Tarazi, Y. (2003) Epidemiology of ovine brucellosis in Awassi sheep in northern Jordan. Prev. Vet. Med., 60(4): 297-306.

4. Mantur, B.G. and Amarnath, S.K. (2008) Brucellosis in India - A review. J. Biosci., 33: 539-547.

5. Acha, N.P. and Szyfres, B. (2003) Zoonoses and Communicable Diseases Common to Man and Animals. $3^{\text {rd }}$ ed. Pan American Health Organization (PAHO), Washington, DC. p1.

6. Seleem, M.N., Boyle, S.M. and Sriranganathan, N. (2010) Brucellosis: Are-emerging zoonosis. Vet. Microbiol., 140: 392-398.

7. Sulima, M. and Venkataraman, K.S. (2010) Economic losses due to Brucella melitensis infection in sheep and goats. Tamilnadu. J. Vet. Anim. Sci., 6(4): 191-192.

8. Smith, H.L. and Kadri, S.M. (2005) Brucellosis in India: A deceptive infectious disease. Indian J. Med. Res., 122(5): 375-384.

9. Webb, R.F., Quinn, C.A., Cockram, F.A. and Husband, A.J. (1980) Evaluation of procedures for the diagnosis of Brucella ovis infection in rams. Aust. Vet. J., 56(4): 172-175.

10. Burgess, G.W. (1982) Ovine contagious epididimytis: A review. Vet. Microbiol., 7(6): 551-575.

11. Nicoletti, P. (1980) The epidemiology of bovine brucellosis. Adv. Vet. Sci. Comp. Med., 24: 69-84.

12. Thakur, S.D., Thapliyal, D.C. and Kumar, M. (2003) Current status of sero-diagnosis of brucellosis. J. Immunol. Immunopathol., 5(1): 12-26.
13. Batra, H.V. (1989) Dot-enzyme linked immunosorbent assay for the detection of antibodies in bovine brucellosis. Res. Vet. Sci., 46(2): 143-146.

14. Bulletin of animal husbandry and dairying statistics, Gujarat (2011-12). Retrieved from http;//doah.gujarat.gov.in/statistics.html

15. Alton, G.G., Jones, L.M., Angus, R.D. and Verger, J.M. (1988) Techniques for Brucellosis. Institute National de le recherché Agronomique, 174 de luniversite, 75007, Paris.

16. Samad, A., Awaz, K.B. and Sarkate, L.B. (1994) Diagnosis of bovine traumatic reticulo peritonitis I: Strength of clinical signs in predicting correct diagnosis. J. Appl. Anim. Res., 6: 13-18.

17. Shome, R., Shome, B.R., Deivanai, M., Desai, G.S., Patil, S.S., Bhure, S.K. and Prabhudas, K. (2006) Seroprevalence of brucellosis in small ruminants. Indian $J$. Comp. Microbiol. Immunol. Infect. Dis., 27(1): 13-15.

18. Singh, S.V., Agarwal, G.S., Batra, H.V., Gupta, V.K. and Singh, N. (2000) Monitoring of Brucella infection associated with reproductive losses using multiple serological tests in organized goat and sheep flocks. Indian J. Anim. Sci., 70(2): 154-156.

19. Teshale, S., Muhie, Y., Dagne, A. and Kidanemariam, A. (2006) Seroprevalence of small ruminant brucellosis in selected districts of Afar and Somali pastoral areas of Eastern Ethiopia: The impact of husbandry practice. Rev. Med. Vet., 2006;157(11): 557-563.

20. Ashenafi, F., Teshale, S., Ejeta, G., Fikru, R. and Laikemariam, Y. (2007) Distribution of brucellosis among small ruminants in the pastoral region of Afar, eastern Ethiopia. Rev. Sci. Tech., 26: 731-739.

21. Esendal, O.M., Yardımc, H., Keskin, O. and Altay, G. (2001) The use of conventional tests and Coombs test in the serological diagnosis of bovine, ovine and caprine brucellosis. Ankara Univ. Vet. Fak., 48(1): 97-102.

22. Valarmathy, K., Kumar, M., Singh, J.L. and Ananda, B.V. (2007) Seroepidemiological study of brucellosis in sheep and goats in Uttarakhand. J. Vet. Public Health, 5(1): 45-47.

23. Lone, I.M., Ashraf, B.M., Maroof, S.M., Asif, I. and Aabeen, S. (2013) Seroprevalence of brucellosis in sheep of organized and unorganized sector of Kashmir valley. Vet. World, 6(8): 530-533.

24. Rahman, M.S., Ali Hahsin, M.F., Ahasan, M.S., Her, M., Kim, J.Y., Kang, S. and Jung, S.C. (2011) Brucellosis in sheep and goat of Bogra and Mymensingh districts of Bangladesh. Korean J. Vet. Res., 51(4): 277-280.

25. Din, A.M.U., Khan, S.A., Ahmad, I., Rind, R., Hussain, T., Shahid, M. and Ahmed, S. (2013) A study on the seroprevalence of brucellosis in human and goat populations of district Bhimber, Azad Jammu and Kashmir. J. Anim. Plant Sci., 23(1): 113-118.

26. Kotadiya, A.J. (2012) Serological, cultural and molecular detection of Brucella infection of sheep in Gujarat. M. V. Sc. Thesis Submitted to Sardarkrushinagar Dantiwada Agriculture University, Sardarkrushinagar, Gujarat.

27. Tayshete, S.R. (2001) Seroprevalence of brucellosis in North Gujarat. M. V. Sc. Thesis Submitted to S. D. A. University, S.K. Nagar, Gujarat.

28. Awandkar, S.P., Gosavi, P.P., Khode, N.V., Jadhav, S.G., Mendhe, M.S., Kulkarni, M.B. and Sardar, V.M. (2012) Seroepidemiology of brucellosis in sheep. Indian Vet. J., 89(6): 30-31.

29. Hassanain, N.A. and Ahmed, W.M. (2012) Sero-prevalence of brucellosis in Egypt with emphasis on potential risk factors. World J. Med. Sci., 7(2): 81-86.

30. ICAR Annual Report (2009-2010), Livestock Management. Retrieved from http://www.icar.org.in/en/node/1107 